\title{
Medicina alternativa resguardada na memória dos sujeitos entrelaçada com o ensino da química na escola
}

Alternative medicine sheltered in the memory of the subjects intertwined with the teaching of chemistry in the school

Medicina alternativa resguardada en la memoria de los sujetos entrelazados con la enseñanza de la química en la escuela

Afonso Abreu Coutinho Professor Especialista, SEDUC-MT, Brasil. afonsoabreucoutinho@gmail.com

Thiago Beirigo Lopes Professor Mestre, IFMT, Brasil. thiagobeirigolopes@yahoo.com.br

Marcelo Franco Leão Professor Mestre, IFMT, Brasil. marcelofrancoleao@yahoo.com.br 
RESUMO

Nesse estudo, de caráter científico e pedagógico, foi enfatizada a participação ativa dos estudantes durante o processo de aprendizagem, quanto a tomada de decisão como condição para a construção de conhecimentos. Partindo dessa perspectiva, em que a participação e envolvimento dos estudantes é determinante para se obter sucesso, é que desenvolvemos essa prática pedagógica baseada na aprendizagem significativa e que utiliza a pesquisa como estratégia de estudo. A proposta foi desenvolver um levantamento etnobotânico de plantas com usos terapêuticos no município de Porto Alegre do Norte-MT, estimar a diversidade de espécies usadas, suas funções e estrutura química. Para coletar dados, os estudantes do 3 o ano do Ensino Médio da Escola Estadual 13 de Maio, entrevistaram 18 pessoas adultas de ambos os sexos, buscando se entender o modo de utilização de forma sistêmica, suas formas de preparo, consumo e indicação. Identificaram-se 66 espécies, pertencentes a 26 famílias. Das quais foram selecionadas 10 ervas mais utilizadas, com a finalidade de estudar a sua estrutura química e suas funções. Os resultados mostram que as práticas e saberes culturais relacionados com a utilização de plantas medicinais ainda podem ser encontrados nesse município. Sendo assim, é de grande importância a integração de estudos que dimensionem o potencial de uso de plantas medicinais do cerrado, visando a formulação de práticas que conservem este bioma.

PALAVRAS-CHAVE: Plantas medicinais. Estrutura química. Aprendizagem significativa. Medicina popular.

\section{ABSTRACT}

In this study, of a scientific and pedagogical nature, it was emphasized the active participation of the students during the learning process, as well as the decision making as a condition for the construction of knowledge. From this perspective, in which student participation and involvement is determinant for success, we develop this pedagogical practice based on meaningful learning and that uses research as a study strategy. The proposal was to develop an ethnobotanical survey of plants with therapeutic uses in the city of Porto Alegre do Norte-MT, to estimate the diversity of species used, their functions and chemical structure. In order to collect data, the students of the 3rd year of the High School of the State School 13 de Maio, interviewed 18 adult people of both sexes, trying to understand the systemic way of using it, its forms of preparation, consumption and indication. A total of 66 species belonging to 26 families were identified. Of the 10 most used herbs were selected, with the purpose of studying its chemical structure and its functions. The results show that cultural practices and knowledge related to the use of medicinal plants can still be found in this municipality. Therefore, it is of great importance the integration of studies that dimension the potential of use of medicinal plants of the cerrado, aiming the formulation of practices that conserve this biome.

KEY WORDS: Medicinal plants. Chemical structure. Meaningful learning. Popular medicine.

\section{RESUMEN}

En este estudio, de carácter científico y pedagógico, se enfatizó la participación activa de los estudiantes durante el proceso de aprendizaje, en cuanto a la toma de decisión como condición para la construcción de conocimientos. A partir de esta perspectiva, en la que la participación e implicación de los estudiantes es determinante para obtener éxito, es que desarrollamos esta práctica pedagógica basada en el aprendizaje significativo y que utiliza la investigación como estrategia de estudio. La propuesta fue desarrollar un levantamiento etnobotánico de plantas con usos terapéuticos en el municipio de Porto Alegre do Norte-MT, estimar la diversidad de especies usadas, sus funciones y estructura química. Para recoger datos, los estudiantes del 30 año de la Enseñanza Media de la Escuela Estadual 13 de Mayo, entrevistaron a 18 personas adultas de ambos sexos, buscando entender el modo de utilización de forma sistémica, sus formas de preparación, consumo e indicación. Se identificaron 66 especies, pertenecientes a 26 familias. De las cuales fueron seleccionadas 10 hierbas más utilizadas, con la finalidad de estudiar su estructura química y sus funciones. Los resultados muestran que las prácticas y los saberes culturales relacionados con la utilización de plantas medicinales todavía pueden ser encontrados en ese municipio. Por lo tanto, es de gran importancia la integración de estudios que dimensionen el potencial de uso de plantas medicinales del cerrado, buscando la formulación de prácticas que conserven este bioma.

PALABRAS CLAVE: Plantas medicinales. Estructura química. Aprendizaje significativo. Medicina popular. 


\section{INTRODUÇÃO}

No Brasil, o uso das espécies vegetais, com fins de tratamento, cura de doenças e sintomas, remonta ao início da civilização. Basta tomar como referência a organização das populações tradicionais. Desde o momento em que o homem despertou para a consciência e começou um longo percurso de manuseio, adaptação e modificação dos recursos naturais para o seu próprio benefício. Essa prática milenar ultrapassou todas as barreiras e obstáculos chegando até os dias atuais, sendo amplamente utilizado por grande parte da população mundial como fonte de recurso terapêutico eficaz (DI STASI, 1996). Há mais de seis mil anos o homem vem testando e escolhendo instintivamente as melhores plantas medicinais para curar suas doenças. Porém, a cada dia, as plantas ganham seu espaço como aliadas no reequilíbrio físico do homem (SIXEL, 1998).

Para a Organização Mundial da Saúde (OMS), plantas medicinais são todas aquelas, silvestres ou cultivadas utilizadas como recursos para prevenir, aliviar, curar ou modificar um processo fisiológico normal ou patológico, ou como fonte de fármacos e de seus precursores (ARIAS,1999). Silva-Almeida e Amoroso (1998) salientam que o papel das plantas medicinais no cotidiano das populações humanas tem sido objeto de estudo ao longo dos tempos, buscando identificar a comunidade estudada. As espécies vegetais com suas diferentes utilidades estão incorporadas à economia da sociedade, às práticas acadêmicas, entre outros. $\mathrm{O}$ estudo das plantas medicinais e seu uso empírico para tratar diversos males tem proporcionado a descoberta de medicamentos importantes, onde seus princípios ativos atualmente são a arma obrigatória no combate às certas doenças do coração.

Outro aspecto a ser considerado é que na contemporaneidade é preciso pensar em uma prática pedagógica que possibilite refletir sobre a participação efetiva dos estudantes, ou seja, é preciso reconhecer o conhecimento humano enquanto construção e o processo participativo.

Por acreditar que a participação efetiva dos estudantes no processo educativo e que definição de estratégias e conteúdos a serem explorados em sala de aula são condições fundamentais para a construção de aprendizagens significativas, assim como indica Ausubel (2003), é que se propôs essa intervenção pedagógica. Partir do estudo de plantas medicinais teve o propósito de relacionar o conhecimento popular e os conceitos científicos, em especial os de Química, amplamente envolvidos.

A luz da concepção de Micotti (1999) as condições para um desenvolvimento pessoal, alicerçado em sua auto-expressão criadora e em sua autoconstrução, possibilita uma aprendizagem significativa, alicerçada em uma prática professor, que "coloca a necessidade de trabalho didático, organizado de modo a atender o ritmo de desenvolvimento dos aprendizes, voltado para a passagem do conhecimento individual em saber socializado" (MICOTTI, 1999). Logo, esse trabalho voltado para o ensino de Química tendo como temática as plantas medicinais destinam-se a aqueles que desejam refletir sobre a prática professor e o processo de construção do conhecimento, por meio de aulas orientadas. Buscou-se fazer além do levantamento das plantas medicinais do município de Porto Alegre do Norte - MT, a estimativa 
da diversidade de espécies mais utilizadas, bem como as funções e estrutura química presentes nessas plantas.

\section{ENSINO DE QUÍMICA CONTEXTUALIZADO E A APRENDIZAGEM SIGNIFICATIVA}

Assim, "ensinar não é transferir conhecimentos, conteúdos, nem formar é ação pelo qual o sujeito criador dá forma, estilo ou alma a um corpo acomodado" (FREIRE, 1996). Neste processo ensinar inexiste sem aprender e vice-versa e ambos são processos historicamente de descoberta, de investigação.

Ainda sob a perspectiva de Freire (1996), o professor não pode se negar o dever de em sua prática reforçar a capacidade crítica do estudante, sua curiosidade, sua insubmissão. Para tanto uma das tarefas primordiais é trabalhar com os estudantes a "rigorosidade metódica" no ato de ensinar. Neste sentido, ensinar não se esgota no tratamento do objeto ou do conteúdo, superficialmente feito, mas se alonga à produção das condições em que aprender criticamente é possível. É essas condições de ensino-aprendizagem que exigem professores e estudantes criadores, instigadores, inquietos, curiosos, humildes e persistentes.

Ensinar à luz da teoria progressista exige pesquisa, pois segundo Freire $(1996$, p. 47)

[...] não existe ensino sem pesquisa e pesquisa sem ensino, ambos se encontram um no corpo do outro. Enquanto ensino contínuo buscando reprocurando. Ensino porque busco, porque indaguei, porque indago e me indago. Pesquiso para constatar, constatando intervenho, intervindo educo e me educo.

Nesta linha de pensamento Perrenoud (2000), fala que para ter-se uma escola mais eficaz para todos, organizar e dirigir situações de aprendizagem é necessário manter um espaço justo para tais procedimentos. É, sobretudo, despender de energia e tempo e dispor das competências profissionais necessárias para imaginar e criar outros tipos de situações de aprendizagens, que as didáticas contemporâneas encaram como situações amplas, abertas, carregadas de sentido de regulação, as quais requerem um método de pesquisa, de identificação e resolução de problemas.

Neste sentido é necessário que a prática professor se envolva em "um movimento dinâmico, dialético, entre o fazer e o pensar sobre o fazer" (FREIRE, 1996). É necessário voltar-se sobre si mesma, através da reflexão sobre a prática, para que a curiosidade ingênua vá se tornando crítica, à luz da teoria que a ela dá sustentação, pois "o meu discurso sobre a Teoria, deve ser o exemplo concreto, prático da teoria" (FREIRE, 1996).

Segundo Chizzotti (2001), "o ensino não pode restringir-se à mera transmissão dos conhecimentos já acumulados, e o aprendizado não pode reduzir-se à acumulação de informações". Ainda o autor aborda que o ensino precisa ter significado, e ele só ganha um novo significado quando propicia o prazer da descoberta e a importância do conhecer, quando 
provoca a observação, mobiliza a curiosidade, move a busca de informações, esclarece dúvidas e orienta as ações, suprindo as necessidades vitais do estudante.

Segundo Freire (1996) ao falar de construção do conhecimento, os sujeitos devem envolver-se no processo e estarem predispostos às mudanças, à aceitação do diferente diante dos outros e do mundo enquanto ser cultural, histórico, inacabado e consciente do inacabamento.

Neste trabalho, e especificamente para a execução da pesquisa, além de Freire (1996), Perrenoud (2000) e outros teóricos que contribuíram para a compreensão do processo de desenvolvimento do ensino aprendizagem, também se fizeram necessário analisarmos alguns fundamentos com abordagem na etnobotânica, química e farmacologia, procurando intercalar as conceituações desenvolvidas pelo grupo de entrevistados, a respeito do mundo vegetal e a classificação das plantas e a sua utilização.

É notório afirmar que a pesquisa propicia essa visualização da relação entre homem e natureza, pois como diz Añez (1999): "Já não consigo ver a planta pela planta, nem o homem pelo homem. Para qualquer um dos dois que eu olho, o outro é a parte integrante". Isso indica que há uma interação muito grande entre homem e a natureza, caracterizada não como uma relação de dependência, mas sim como uma inter-relação de vivência social.

Cale destacar ainda que várias espécies vegetais vêm sendo utilizadas por diferentes culturas entre os seres humanos, especialmente entre os povos de origem africana e indígena, como uma das principais formas de tratamento à sua saúde. Revelando, assim, que a natureza e a cultura estão intimamente ligadas ao saber popular medicinal, o que pode claramente ser percebido neste trabalho.

\section{PROCEDIMENTOS METODOLÓGICOS}

Considerando o propósito da Escola Estadual 13 de Maio em se firmar como espaço de produção e socialização do saber, assumindo a perspectiva que estas duas instâncias não se separam no processo educativo, faz-se opção pela corrente pedagógica progressista. Onde segundo Freire (1996) "a reflexão crítica sobre a prática se torna uma exigência da reflexão Teoria/Prática sem a qual a teoria pode ir virando blábláblá e a prática ativismo", e dentro dessa linha político-educacional pretende-se trabalhar com a matriz de significado da metodologia da problematização.

A metodologia da problematização permite a relação ação-reflexão-ação como eixo básico de orientação do processo ensino-aprendizagem, apoiada nos fundamentos da pedagogia crítica, tendo como meta o desenvolvimento da conscientização do sujeito que aprende considerando a realidade que se encontra inserido. Nesta perspectiva, se apresenta como processo sistematizado em consonância com as etapas como explica Freire (1996): 
(I) observação da realidade (problema) $\rightarrow$ (II) postos-chave $\rightarrow$ (III) teorização $\rightarrow$ $\rightarrow$ (IV) hipóteses de solução $\rightarrow$ (V) aplicação à realidade.

Para esse trabalho foram realizadas entrevistas semiestruturadas, com perguntas abertas, sobre plantas usadas para curar ou prevenir doenças, formas de preparo, parte da planta utilizada e listagem livre das plantas usadas pelos entrevistados, seguindo as seguintes etapas de desenvolvimento:

a) Obtenção de dados socioeconômicos dos entrevistados.

b) Levantamento das plantas utilizadas como medicinais na comunidade.

c) Identificação das espécies.

d) Revisão na literatura científica de cada espécie, obtendo informações sobre o uso popular, a composição química, a atividade farmacológica estabelecida, por meio de levantamentos em livros específicos da área e dados em publicações científicas disponíveis na internet.

As entrevistas foram realizadas pelos estudantes do 30 Ano do Ensino Médio, da Escola Estadual 13 de Maio. Foram entrevistadas 18 pessoas, entre 30 e 60 anos de idade, os que trabalham com plantas medicinais como alternativa de cura e os que utilizam como bem-estar para a saúde da família.

Além das entrevistas semiestruturadas, com perguntas abertas, sobre plantas usadas para curar ou prevenir doenças, formas de preparo, parte da planta utilizada e listagem livre das plantas usadas pelos entrevistados, foram realizados estudos sobre a composição química de algumas dessas plantas com a finalidade de compreender seus arranjos estruturais. Essas atividades foram baseadas nos estudos de Souza (1998) que investigou o uso de plantas medicinais por moradores do município de Acorizal - MT.

A proposta foi levantar os saberes populares e, a partir desses, estudar os conceitos científicos envolvidos, bem como tornar o estudo da química mais significativo, por meio de um ensino contextualizado e interdisciplinar.

\section{RESULTADOS E DISCUSSÕES}

Foram mencionadas sessenta e seis (66) diferentes plantas medicinais utilizadas. Essas espécies estão distribuídas em 33 famílias, dentre elas: Lamiaceae, Asteraceae, Apiaceae, Verbenácea e Euforbiácea. As plantas indicadas como sendo as mais utilizadas foram: camomila (14), erva-doce (15), limão (10), acerola (5), hortelã (3), alecrim (2), canela (2) e eucalipto (2). No Quadro 1 cada uma dessas espécies é apresentada de acordo com seu nome popular, nome científico, função orgânica e substâncias características que contém. 
Quadro 1: Identificação das dez substâncias mais utilizadas pelos entrevistados.

\begin{tabular}{|c|c|c|c|c|}
\hline $\begin{array}{l}\text { Nome } \\
\text { Popular }\end{array}$ & Nome Científico & Função Orgânica & $\begin{array}{c}\text { Substância } \\
\text { Característica }\end{array}$ & Estrutura Química \\
\hline Eucalipto & $\begin{array}{l}\text { EukalyptusgloculosL } \\
\text { abill. }\end{array}$ & Aldeído & $\begin{array}{c}\text { Eucaliptol/Citronela } \\
\text { /Cânfora }\end{array}$ & $\mathrm{CH}_{3}$ \\
\hline Hortelã & Metha $x$ villosaHuds & Álcool & $\begin{array}{l}\text { Menthol/ } \\
\text { Limoneno }\end{array}$ & \\
\hline Limão & Citrusaurantifolia & $\begin{array}{l}\text { Hidrocarboneto } \\
\text { (Terpeno) }\end{array}$ & Limoneno & \\
\hline Erva-doce & Foeniculumvulgare & Cetona & Carvona & \\
\hline Canela & $\begin{array}{c}\text { Cinnamomumzeylnic } \\
\text { um }\end{array}$ & Éter/Fenol & Eugenol & \\
\hline Alecrim & Rosmarinusoficinalis & Cetona & Cânfora & \\
\hline Erva cidreira & Melissa officinalis & Aldeído & Citronelal & \\
\hline Acerola & Malphighia glabra L. & Álcool/Éster & Ácido Ascórbico & \\
\hline Gengibre & Zingibreoffinalerosc & $\begin{array}{c}\text { Alcool/Cetona/Fenol } \\
\text { /Éter }\end{array}$ & Gingerol & \\
\hline Camomila & $\begin{array}{c}\text { ChamomillarecutitaL } \\
\text {.Rauschert }\end{array}$ & Álcool/Cetona/Éster & Fenolina & \\
\hline
\end{tabular}

Fonte: Dados coletados na pesquisa (2016).

Ao serem questionados, sobre quais partes das plantas que utilizam com fins medicinais, as respostas foram: folhas (18), casca (7), flor (5), raiz (2), semente (2), broto (1), fruto (1), haste (1) e planta inteira (1). Observou-se também que $80 \%$ dos entrevistados utilizam-nas em forma de chás e $20 \%$ de outras formas, como: garrafada, xarope, sumos, sucos, banhos, entre outras. Os entrevistados são naturais de diversos estados brasileiros. Sendo, 4 deles naturais do Maranhão, 3 do Pará, 3 do Tocantins, 3 de Mato Grosso, 2 de Goiás, 1 da Bahia, 1 de Minas Gerais e 1 natural do estado do Piauí. Referente a escolarização dos entrevistados, 11 deles não são alfabetizados, 5 possuem escolarização entre 1a a 4a série e os outros 2 entre 5 a e $8^{\text {a }}$ série do Ensino Fundamental. Dentre os 18 entrevistados, 11 deles se declaram pertencentes a classe baixa, 6 deles classe média e apenas 1 se declarou pertencente a classe alta. 
Ao todo foram selecionadas dez plantas mais utilizadas pelos agentes envolvidos na pesquisa, foram organizadas em ordem alfabética - famílias botânicas, nome vulgar da espécie, nome científico, indicação e formas de uso, e estão apresentadas em forma de tabela no corpo do trabalho. Para preservar a identidade dos entrevistados, eles foram identificados como Entrevistado 1, Entrevistado 2 e assim por diante.

Conforme podemos observar na fala de Entrevistado 1, quando diz: "[...] de primeiro o povo se curava com o remédio do mato, agora toda coisa é doutor, doutor, perde a fé de Deus, tem tanto remédio bom do mato. Aqui tem muita gente que usa remédio caseiro, porque tem gente que é fraca de recurso. Tem muitas coisas que é alimento e servem de remédio".

Cabe salientar que nem sempre o uso de plantas medicinais está atrelado ao fator econômico, mas também aos fatores étnico-culturais, sociais e outros. No Quadro 2, as plantas mais lembradas pelos entrevistados estão acompanhadas com a indicação, ou seja, em que situações são utilizadas e a forma de uso das mesmas.

Quadro 2: Plantas medicinais utilizadas, indicação e forma de uso

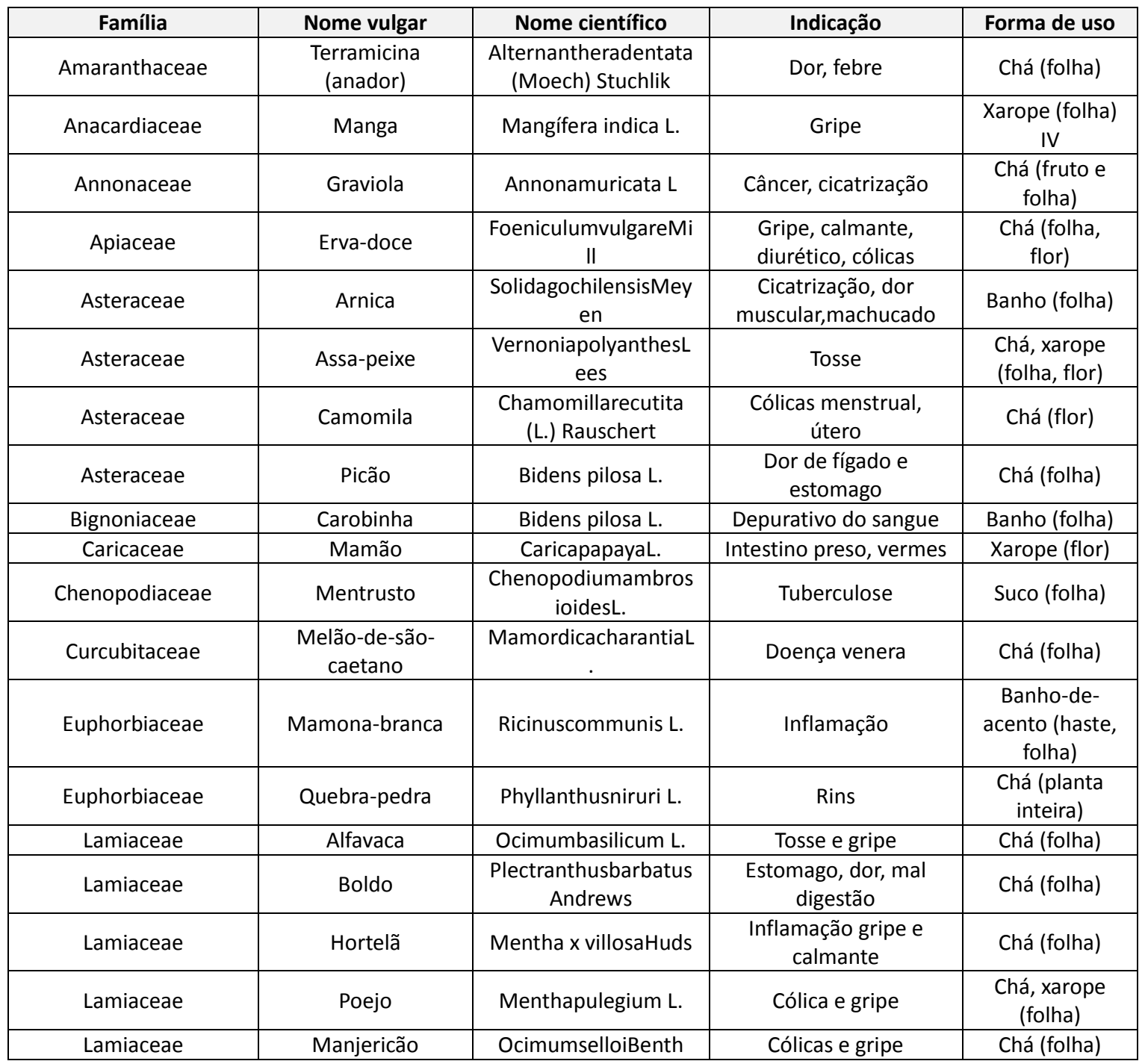


fitoterapia. Observe na fala do Entrevistado 2, como se dá a transmissão destes conhecimentos:

O lixo transmite muita doença ele traz (hanseníase, dengue, malária, hepatite, AIDS) doença que ninguém sabe trata, antigamente nós banhava na enxurrada não dava nem dor nas junta. Hoje muito micróbio de bicho morto. Desde menina, minha mãe mexia eu fui prendendo. Quando minha mãe morreu eu tinha nove anos, morei com minha madrinha que aprendeu com o povo antigo, a mãe de madrinha era muito indigesta.

Com base no Quadro 2 e nos depoimentos abaixo, o uso de plantas medicinais apresenta-se como um dado interessante devido ao ritual da colheita e do preparo, rituais estes aprendidos na prática, passados de geração em geração e que continuam fazendo parte da história deste povo.

Para tirar os paus do mato- tanto faz, tem uns que arranca a raiz, outros na árvore, o Baru, jatobá, tira na arvore, tem deles que tem ciência, a mangabeira tem que tirar a raiz do lado que o sol nasce, a gente aprendeu assim (Entrevistado 2).

Tem sistema para tirar, principalmente feminino. Baru, tem ciência, conforme o problema. Se esta desmantelada do lado que o sol sai de cima para baixo, se está demais, do lado que o sol sai, de baixo para cima (Entrevistado 3).

Para tirar um ramo da planta precisa de cuidado, batizar o ramo, rodear ele três vezes, arranca com o cavador de pau. Pela lua, estando cheia não serve porque está aumentando, sempre na parte da minguante. Pela nova quando vai pra minguante está no tempo de preparar (Entrevistado 4).

Casca da aroeira, do lado que o sol sai, e fala pelo amor de Deus me dá uma casca pra um remédio. Descasca, pisa Põe no sol pra seca, depois faz remédio (Entrevistado 5).

Com relação às doenças e seus possíveis tratamentos a partir do uso de ervas medicinais foram citados pelos entrevistados 59 (cinquenta e nove doenças) e os respectivos tratamentos, os quais estão descritos em ordem alfabética no presente trabalho conforme os mais comentados e usados popularmente: 
Quadro 3: Doenças e tratamento com o uso de ervas medicinais conforme as entrevistas

\begin{tabular}{|c|c|}
\hline DOENÇAS & TRATAMENTO COM USO DE ERVAS MEDICINAIS \\
\hline Anemia & Chá da casca de jatobá. \\
\hline Calmante & Folha de laranja sem doce. Ferver a água e colocar em cima. \\
\hline Bronquite Asmática & $\begin{array}{l}\text { Murchas a folha santa, tirar a água, misturar com o mel e beber. Folha de eucalipto, gengibre, } \\
\text { entre casca da manga (lado que o sol sai). Torrar bem torradinha, fazer o chá e o colocar uma } \\
\text { gota de óleo de pau. }\end{array}$ \\
\hline Câncer & Bater babosa com o vinho branco e mel. \\
\hline Catapora & Chá da folha de sabugueiro. \\
\hline Cólicas & Tirar o sumo de boldo liso e tomar. \\
\hline Coluna & $\begin{array}{l}\text { Chá de candeia Chá de mangaba mansa. Pegar } 18 \text { formigões com uma pinça e colocar num litro } \\
\text { de pinga. Deixar } 8 \text { dias, daí sacudir bem, côa Lá para tirar os formigões, lavar o litro, colocar a } \\
\text { pinga novamente no litro. Tomar uma colher de manha e outra a noite. }\end{array}$ \\
\hline Conjuntivite & Colocar um raminho de arruda num copo com água, deixar no sereno, no outro dia lavar o olho. \\
\hline Dor De Barriga/Diarréia & $\begin{array}{l}\text { Chá da entre casca da lixeira que é também chamada de sambaíba. Chá da folha de carne. Chá de } \\
\text { um pedacinho da folha de babosa. Chá de cordão de São Francisco. Chá de pinhão roxo. } \\
\text { Batatinha de coquinho, lavar, pisar, por na água e beber. Chá da vassourinha (tomar e banhar). } \\
\text { Fazer o chá ou tirar o sumo de merindiba ou bacaba ou cega machado e dar para beber. }\end{array}$ \\
\hline Dor De Cabeça & $\begin{array}{l}\text { Chá de erva cidreira cozinha: andu, Mulatinha, folha santa, folha de pinhão, botar no sereno, no } \\
\text { outro dia cedo tomar um banho. Chá de andu, folha santa, malva do reino e depois do chá feito } \\
\text { colocar arruda. Chá de aguardente de planta. Chá da folha de anador. }\end{array}$ \\
\hline Dor De Estômago & Chá de boldo. Pílula de babosa \\
\hline Dor No Corpo & $\begin{array}{l}\text { Fazer um banho bem esperto com negamina, tipí, folha de algodão, folha de manga, Mastruz, } \\
\text { arnica e todo tipo de pau manso. } \\
\text { Fazer uma garrafada de: manacá, sofre do rim quem quer, quebra pedra. Pisar tudo no pilão, } \\
\text { deixar no sereno, no outro dia cozinhar com um pouco de açúcar. } \\
\text { Depois colocar um copo de vinho branco. Deixar dormir três dias no sereno. }\end{array}$ \\
\hline Febre & $\begin{array}{l}\text { Chá de folha de sabugueiro. Chá de raiz de gengibre. Chá da folha de laranja. } \\
\text { Chá de erva cidreira. Chá de casca de laranja. Chá da raiz do capim de cheiro. Chá de mata - } \\
\text { pasto; Chá de fedegoso; Chá de terramicina. Chá de hortelã. }\end{array}$ \\
\hline Fígado & $\begin{array}{l}\text { Chá de boldo. Chá de poejo. Chá de folha de carne. Chá de mangaba brava. Chá de folha de } \\
\text { mamão. Chá da mangabeira. }\end{array}$ \\
\hline Gastrite & $\begin{array}{l}\text { Casca de aroeira. Chá da casca de romã com mastruz. Torrar a moela da ema e com o pó e fazer } \\
\text { o chá para beber. Pisar o jambú, tirar o sumo e tomar por dois meses. Resina de jatobá. Moer e } \\
\text { tomar uma pitada de toda vez que vez que beber água ou comer. }\end{array}$ \\
\hline Inflamação Da Garganta & $\begin{array}{l}\text { Chá de romã. Chá da folha de sabugueiro. Chá de velame do campo. Gargarejo com chá da casca } \\
\text { de romã. Macetar a raiz de fedegoso, por para cozinhar e beber. }\end{array}$ \\
\hline Pressão Alta & $\begin{array}{l}\text { Chá da folha de cana caiana. Chá de folha de tomate. Tomar por três dias. Raspar o gengibre e } \\
\text { tomar com água fria. }\end{array}$ \\
\hline Pressão Baixa & Raspar o gengibre e tomar com água fervida. Chá de cravinho. \\
\hline
\end{tabular}

Fonte: Dados coletados na pesquisa (2016) 
Observou-se que foram citadas doenças das mais comuns às mais complexas, porém para todas são apresentadas soluções de tratamento com base na medicina tradicional, ou seja, com plantas medicinais. Porém os entrevistados declararam que há resistência atualmente a este tipo de tratamento e relaciona esta resistência à perda da fé religiosa, em nenhum momento os entrevistados fazem menção aos perigos que pode ocasionar os usos das plantas medicinais sem o devido conhecimento.

O pessoal de 50 pra trás tem uma resistência e de 50 pra cá tem outra, é porque não sabe se cura na folhagem, só sabe se cura na injeção, acaba as forças (Entrevistado 3).

A amostragem foi realizada pelos estudantes do 3 Ano do Ensino Médio da Educação de Jovens e Adultos, com o auxílio de pesquisa bibliográfica e o uso de ferramentas on-line. Foram selecionadas as dez plantas mais utilizada pelos entrevistados e foram identificadas seis funções químicas, como pode se observar no quadro 1 . O limoneno foi encontrado tanto na hortelã quanto no limão.

O mesmo ocorre com a cânfora a qual é encontrada no alecrim e no eucalipto. Na erva-doce e no eucalipto foi encontrada a citronela. $O$ que pode ser observado é que numa única planta pode se encontrar mais que uma função química, como também plantas de espécies diferentes podem possuir função química igual.

As funções químicas foram reconhecidas pelos estudantes com o auxílio do professor, conforme visualização abaixo, tendo como meio um programa computacional ChemSketch 8.0, disponível na Internet. Com isso foi possível identificá-las mais precisamente, observando suas respectivas funções e estrutura. Esta atividade tornou as aulas mais atraentes e significativas, fazendo com que o processo de ensino aprendizagem fosse sendo construído de forma criativa, prazerosa e participativa.

Os estudantes observaram que numa única planta pode se encontrar mais que uma função química, como também plantas de espécies diferentes podem possuir função química igual.

Por meio dessa experiência pedagógica vivenciada nas aulas de Química, percebe-se o quanto os estudantes se desenvolveram e produziram intelectualmente e socialmente após a oportunidade de serem agentes ativos no processo de ensino - aprendizagem. Eles construíram novos saberes por meio de sua ativa participação, tendo como base os saberes que já possuíam pela vivência pessoal, histórica de vida e os conteúdos abordados pela disciplina, dos quais participaram na elaboração de estratégias para executá-los. Assim, pudemos perceber as três dimensões relacionais que o saber estabelece, ou seja, a relação consegue próprio, com o outro e com o mundo.

Isso corrobora o pensamento de Ausubel (2003), ao afirmar que para ocorrer aprendizagem significativa é preciso ter pré-disposição em aprender, que os conhecimentos prévios são importantes e precisam ser considerados para servirem de suporte no qual uma nova informação, um novo conceito possa ser ancorado. 
No que se refere à relação com o mundo, os estudantes passaram a ter maior interesse pela sua comunidade estendendo este interesse à comunidade global. E especificamente na disciplina de Química, o ensino e a aprendizagem tornaram significativos, pois os conteúdos trabalhados fizeram sentido para os estudantes, o que nos faz entender que a escola, o ensino e a aprendizagem só têm sentido para o estudante quando utilizam elementos de sua realidade quando a vida escolar e a vida do estudante estão relacionadas, ou seja, quando a educação é a própria vida.

\section{CONSIDERAÇÕES FINAIS}

Apresentar intervenções pedagógica é resultado de uma ação em que os estudantes utilizaram diferentes maneiras para estudar, dentre elas a pesquisa, cuja intenção foi fazer com que as aulas de química possibilitem a construção de conhecimentos, não só com repasses de conceitos e conteúdos programáticos, mas que possibilitou estabelecer relações entre os saberes populares e científicos.

Neste sentido, o estudo sobre as plantas medicinais, fez com que os estudantes aproximassem os conceitos científicos (em especial os conceitos químicos) com o cotidiano. Esse conhecimento sobre as plantas medicinais, as quais simbolizam como único recurso terapêutico de muitas comunidades ou grupos étnicos, não pode ser vista e analisada fora dos contextos sociais.

As observações dos saberes populares sobre o uso e a eficácia das plantas medicinais contribuem de forma relevante para a divulgação das virtudes terapêuticas dos vegetais, prescritos com frequência pelos efeitos medicinais que produzem, apesar de não terem seus constituintes químicos conhecidos.

Dessa forma, usuários de todo o mundo, mantém em voga a prática do consumo de fitoterápicos, tornando válidas as informações terapêuticas que foram sendo acumuladas durante séculos. De maneira indireta este tipo de cultura medicinal desperta o interesse de pesquisadores envolvendo áreas multidisciplinares, como por exemplo, a botânica, a farmacologia e a fotoquímica, que juntas enriquecem os conhecimentos sobre a inesgotável fonte medicinal natural.

É sabido que com a expansão da sociedade e o surgimento de novas doenças infecciosas, sobretudo o processo de industrialização dos medicamentos farmacêuticos, e do conhecimento produzido pela academia, esses fatores fizeram com que a medicina natural fosse perdendo cada vez mais a credibilidade enquanto espaço de saúde. No entanto essa pesquisa revelou que essas práticas ainda estão presentes na sociedade.

Consideramos, no entanto, ser importante destacar que não se trata de abdicar dos recursos disponíveis no campo da ciência e da indústria terapêutica, uma vez que a distribuição dos medicamentos farmacêuticos sejam eles gratuitos ou não garantirá uma melhor qualidade vida para as pessoas. Por outro lado, reafirmamos a necessidade de ampliação de pesquisas voltadas para a compreensão acerca da prática da medicina alternativa, de modo que é preciso produzir conhecimentos a partir das memórias das pessoas idosas, que possuem conhecimento sobre essa medicina. 


\section{REFERÊNCIAS BIBLIOGRÁFICAS}

AÑES, R. B. S, O uso de plantas medicinais na comunidade de Garcês (Cáceres, Mato Grosso). 1999. 157 f. Cuiabá: Dissertação (Mestrado Saúde e Ambiente) - Universidade Federa de Mato Grosso, 1999.

ARIAS, T. D, Glossário de medicamentos: desarrollo, evaluación y uso de terminos especializados para la evaluación de medicamentos. Washigton: Organización Pan- Americana de Salud, 1999.

AUSUBEL, D. P. Aquisição e retenção de conhecimentos: uma perspectiva cognitiva. Lisboa: Plátano, 2003.

CHIZZOTTI, A. Metodologia do ensino superior: o ensino com pesquisa. In: CASTANHO, S; CASTANHO, M. E. (Org.) Temas e textos em metodologia do ensino superior. 2a ed. Campinas: Papirus, 2001.

DI STASI, L. C. Plantas Medicinais: arte e ciências, um guia de estudo interdisciplinar. São Paulo: UNE, 1996.

FREIRE, P. Pedagogia da Autonomia: saberes necessários à prática educativa. São Paulo: Paz e Terra, 1996.

MICOTTI, M. C. O. O ensino e as propostas pedagógicas. In: BICUDO, M. A. V. Pesquisa em educação matemática: concepções e perspectivas. São Paulo: Editora da UNESP, 1999.

PERRENOUD, P. Dez Novas competências para ensinar. Tradução de Patrícia Chittoni Ramos. Porto Alegre: Artes Médicas Sul, 2000.

SILVA- ALMEIDA, M. F; AMOROZO, M. C.M. Medicina Popular no distrito de Ferráz, município do Rio Claro, estado de São Paulo. Brasilian Journl of Ecology, v.2, n.1, 1998.

SIXEL, P. J. O resgate das plantas medicinais e da fitoterapia. Revista Centro Ciências Médicas, v. 2, n. 2, 1998.

SOUZA, L. F. Estudo etnobotânico na comunidade de Baús: o uso de plantas medicinais (município de Acorizal, Mato Grosso). 1998. 122 f. Cuiabá: Dissertação (Mestrado Saúde e Ambiente) - Universidade Federa de Mato Grosso, 1998. 